\title{
A Snapshot of Image-Based Sexual Abuse (IBSA): Narrating a Way Forward
}

\author{
Brandon Sparks ${ }^{1}$ (D)
}

Accepted: 18 April 2021 / Published online: 27 April 2021

() The Author(s), under exclusive licence to Springer Science+Business Media, LLC, part of Springer Nature 2021

\begin{abstract}
Introduction The rise of technology has ushered in a new means of sexual expression, commonly referred to as sexting, which involves the sending of sexual messages or images of oneself to another person. Growing in popularity particularly among youth and young adults, the sending of images to current or potential romantic or sexual partners is increasingly becoming part of courting and relationship maintenance rituals. Yet this new domain of sexual agency has been met with a rise in the non-consensual dissemination of intimate or nude photographs to third parties, in some cases to humiliate or shame the creator of the image.

Methods This paper uses a socio-narratological approach to understand the complex consequences that (largely female) victims of image-based sexual abuse (IBSA) experience.

Results Individuals who experience IBSA may undergo perpetuated suffering due to an interwoven constellation of internal and external forces, much of which is rooted in the sexual regulation (if not subjugation) of women. Suffering is presented as originating from three domains: the self, the perpetrator, and society, which interact as a "Dark Triad."

Conclusions The use of socio-narratology to disentangle the suffering may provide victims and mental health professionals with experiential clarity. Further, it offers a way forward for individuals who have experienced this unique form of sexual violence.
\end{abstract}

Keywords Image-based sexual abuse $\cdot$ Revenge pornography $\cdot$ Sexual violence $\cdot$ Sexuality $\cdot$ Romantic relationships . Sexual ethics

A month after her high school graduation, Jessica Logan hanged herself in her bedroom. Described as "vivacious," "artistic," and "compassionate," the 18-year-old Logan had spent the final year of her life being the subject of intense harassment after a nude image she had sent to her then-boyfriend circulated throughout the area high schools (Celizic, 2009). Two years later, Amanda Todd received information from police that a topless photo of her was being disseminated on the Internet (Huntley, 2012). After a prolonged struggle with alcohol and other drug use, Todd committed suicide at age 15. In 2013, Rehtaeh Parsons was taken off of life support after attempting suicide 3 days prior. The attempt came on the heels of a grueling 18-month period when photographs

Brandon Sparks

brandon.sparks@usask.ca

1 Department of Psychology, University of Saskatchewan, 9 Campus Drive, 154 Arts, Saskatoon, SK, Canada were disseminated depicting the then-15-year-old Parsons' being sexually assaulted while heavily intoxicated.

Despite the fact that all three girls were victims of manipulation and abuse, rather than an outpouring of sympathy, each experienced a considerable amount of harassment at school, being tagged with monikers such as "slut" and "whore" (Celizic, 2009). Parsons' mother claimed that she was "suddenly shamed by almost everyone she knew" (Reese, 2013), forcing her to move to another city where she ultimately took her own life. Todd even received abusive messages after news of a failed suicide was publicized (Huntley, 2012). While all three were teenagers, the experiences of Logan, Todd, and Parsons are echoed by women of all ages, who are coming forward in growing numbers to recount their experiences (Citron \& Franks, 2014). Popular YouTube performer Chrissy Chambers discovered that a former romantic partner had leaked an intimate video of her online years after the couple's relationship had dissolved. In addition to developing posttraumatic stress disorder (PTSD), anxiety, night terrors, and a substance abuse issue, Chambers 
reported to the $\mathrm{BBC}$ that people were commenting on her videos calling her a "whore" and that they lost their adoration for her, unable to "support someone who would choose to do this" (BBC, 2018). English professor Annmarie Chiarini had a series of her intimate images uploaded to a pornography Web site, with others put up for auction on eBay by her then-partner who sent the links to her friends and colleagues (Chiarini, 2013). When she applied for medical leave at the advice of her therapist, the college told her she was ineligible as she was responsible for her partner's non-consensual dissemination.

In addition to the harm caused by the perpetrators of this unique form of abuse, each of these instances was also met with social ridicule or at best, indifference. Discord between one's own self-image and that which was presented to their peers is also apparent. As will be discussed throughout this paper, these are integral considerations in understanding the nature and context of IBSA. With the exception of Parsons, the above victims had all engaged in "sexting," which refers to the sending of sexual material (i.e., texts, images, videos) through text messaging or through other messaging applications such as Instagram or Snapchat. The sharing of such intimate images is largely becoming a new norm in both romantic and sexual relationships with roughly half of survey respondents in their twenties reporting having sent a sexual image or video of themselves to another person (Benotsch et al., 2013; Henderson \& Morgan, 2011; Klettke et al., 2014; Lippman \& Campbell, 2014). A meta-analysis by Mori et al. (2020) found that this trend is growing, with more recent studies reporting the highest prevalence rates. Indeed, a recent national survey of Australians found that $61 \%$ of participants in their twenties had sent at least one sexual image in their lifetime (Henry et al., 2017).

While prevalence rates among emerging adults are relatively consistent across studies - ranging from one third to one half of respondents-estimating the prevalence of intimate image sharing among youth is difficult due to sampling differences and the various definitions employed by researchers regarding what constitutes an intimate or sexual image (Klettke et al., 2014). For instance, only $2.5 \%$ of respondents in a national sample of 1560 youth aged 10-17 reported having even created a nude or sexual image while another school-based survey found that $7.7 \%$ of youth had sent sexual images (Hinduja \& Patchin, 2010; Mitchell et al., 2012). Samples of older youth report greater engagement in sending sexual images, with prevalence rates ranging from 18 to 27\% (Englander, 2015; Strassberg et al., 2013). Given its popularity, is apparent that the sending of intimate images of oneself has emerged as a part of broader "sexting" behaviors, which constitute an important part of sexual expression and sexual/romantic relations.

Unfortunately, out of this new domain of sexual expression has been borne a sinister act in which these intimate images are being shared with others without the permission of the person who originally took and sent the photograph (Uhl et al., 2018). The sharing of another person's intimate images without permission has commonly been referred to as "revenge porn," which has been criticized as not fully encompassing the motives behind the perpetration (Burkett, 2015; DeKeseredy \& Schwartz, 2016; Powell et al., 2018). Others have begun using the term "nonconsensual pornography" to avoid this objection, as it also captures the sexual, monetary, and social gains that facilitate the abusive behavior (Eaton \& McGlynn, 2020; Ruvalcaba \& Eaton, 2019). To fully capture the nature of the acts, the present paper will refer to such technologically facilitated acts as image-based sexual abuse (IBSA), part of a spectrum of sexual violence that also includes "upskirting" (the taking of pictures under someone's skirt or dress), sextortion (the threat of disseminating sexual images to third parties), and "deepfaking" (the alteration of sexual videos and images to portray another person, such as superimposing a person's face on another person's naked body; McGlynn et al., 2017).

Recent estimates suggest that roughly $10 \%$ of respondents have experienced some form of IBSA, which doubles when sextortion is included (Branch et al., 2017; Henry et al., 2017). Mori et al.'s (2020) meta-analysis comes to a similar conclusion, with $15 \%$ of persons admitting to having nonconsensually shared an intimate image with someone other than the intended party, a rate that Henry et al. (2020) warn is continually rising. Most recently, the UK's outdatedly named "Revenge Porn Helpline" reported a surge in reported cases during the COVID-19 lockdown, with more than 50 new reports each week (Price, 2020). While both males and females report experiencing IBSA, it is females who also face sexual double standards which limit their sexual agency and promote misogynistic responses (Borrajo et al., 2015; Priebe \& Svedin, 2013; Marks \& Fraley, 2006; Patella-Ray, 2018; Ringrose et al., 2013). Some have even suggested that this may be particularly salient among non-traditional sexual behaviors, a loosely defined category that includes sexual practices that do not fall within cultural norms, such as consensually nonmonogamous relationships, sexual minority relations, and even sexting Mckinlay \& Lavis, 2020; Thompson et al., 2018).

That individuals who are on the receiving end of IBSA report a slew of negative outcomes ranging from the psychiatric (depression, anxiety, PTSD; Bates, 2017; Bloom, 2014; Stroud, 2014) to the somatic (Ruvalcaba \& Eaton, 2020) to the relational (Bates, 2017) should come as no surprise to anyone familiar with the broader sexual violence literature. In summarizing these experiences, it is integral to use language that reflects the depth of these consequences. While pain is a seemingly accurate and often used (Brown, 2006), Ricœur (2013) would argue that the term pain unintentionally minimizes their experience and that the term suffering would be a more apt descriptor. Regardless of the semantic debate, Ricœur's (2013) construction of suffering offers researchers a means of organizing victim's experiences that also reflects the prolonged anguish that they (often) report. This conceptualization operates along three axes, two of 
which are particularly relevant in the understanding of IBSA victimization. The first is the self-other axis, which reflects the victim's relationship with the outside world. Here, it is argued, the victim is engrossed in their suffering, which separates them from others. This is exacerbated if others struggle to understand the victim's suffering, which may be more prevalent among newer forms of abuse, as others have little experience to relate to. Given IBSA's proximity to more traditional forms of sexual violence, it is important to note that the victim-blaming narratives that populate this realm can also serve to further isolate those who have experienced this new medium of abuse.

The second axis relates to the (in)ability to act, which in itself has four components regarding articulation, action, narration, and esteem. The powerlessness to say, according to Ricœur, occurs when the sufferer is unable to express their distress. This can occur if someone is unable to understand their own suffering or if their opportunities for expression are minimized due to social mores regarding the showing of emotion or of their own actions leading up to the suffering (e.g., that one may experience victim blaming). The second component refers to the lack of power or agency to do something about the suffering. This helplessness is, then, suffering in and of itself. The inability to narrate ties into Ricœur's socio-narratological view of personal identity. Here, an external force has influenced their self-narrative (and thus their subjective identity) in a way that is incongruent with their perception of self. This alone is suffering, and as with the first axis, can be made worse if the new narrative is difficult for others to understand or relate to. Uncertain how to respond or deprived of the ability to put forward their own narrative that helps preserve their integrity or feelings about oneself, the fourth manifestation of suffering occurs.

This understanding of suffering as a loss of autonomy coincides with what many victims of IBSA report (Bates, 2017; McGlynn et al., 2020). This inability to act is viewed as both the source of suffering but also as its result, so that suffering spurs further suffering. In a climate that is still somewhat hostile to female sexual expression (particularly young females; Casper \& Moore, 2009; Smith, 2012) and where legal responses are slow, such a thorough conceptualization of suffering is necessary if we are to gain any understanding of the complex experiences that female IBSA victims may face (Citron \& Franks, 2014; Renold \& Ringrose, 2011). Such will be the purpose of this paper.

These same elements also require a framework of analysis that is equipped to handle a sophisticated network of personal and sociocultural influences that can make each instance of IBSA unique while sharing some central themes. This is what Frank (2010) envisions when he discusses narratology. Narratives serve to disentangle a complex array of information, imposing order so that one is able to comprehend what was formerly a tightly wound ball of confusion.
More specifically, that the stories of individuals-that is, their collection of narratives-work as their guidance system, helping them make meaning of their (and others') experiences. This largely implicit guidance system is a lens, magnifying what information is seemingly relevant while disregarding the rest.

After the selection process, the guidance system also provides pre-existing evaluations about this information. Of course, this is not a linear process, as the selection of information is by definition an evaluation. In essence, pertinent, preconceived evaluations of a scenario influence what information is attended to, and from there, we seek to understand our experiences through these evaluations. As this guidance system is ever-changing by means of the increasing collection of personal stories, both what is attended to and the way this information is evaluated is also dynamic. The stories most central to one's identity and worldview-and therefore the most influential-has been described by some as the inner library (Bayard, 2007). While this too can change, it requires a much greater force to do so; coincidentally, stories that contradict those in the inner library also create the greatest dissonance.

It should not be implied from this that an individual's guidance system is objective or even a means to a finite end. While one could use their guidance system to make decisions on whether to buy a particular used car, the collection of stories serves a much grander, more longitudinal purpose. Frank (2010) breaks this down into two axes. The first suggests how stories can help someone existentially, revealing who they are and connecting them to other humans, institutions, causes, and beliefs. The second axis is used to show individuals what is good (in both themselves and in life) and consequently, what is evil. What makes stories influential is not the mere presence of personal affiliations or degrees of goodness, but rather their interactions in stories-the crossroads in the storylines that help shape who and what a character is, which upon reflection become particularly salient.

Using this story-based framework to understand IBSA victimization gives us a solid foundation upon which to understand the complex array of influences that can interact in the victim's suffering and healing journey. For victims of any crime, this line of inquiry is certainly useful—but for victims of such a novel crime where one's sexual expression is so closely tied, where there are so many default evaluations and where there is so much publicity, it is absolutely essential. In essence, socio-narratology allows us to understand the framing of stories, the mechanisms behind our reaction to stories (both of self and others), and most importantly, how these can be changed. In line with findings from McGlynn et al. (2020) interviews with IBSA victims, who described the impact of their abuse as all-encompassing, disruptive, and pervasive, it is argued here that victims of IBSA face a potential tripartite model of victimization-on 
behalf of the perpetrator, self, and society - that interact in such a way to perpetuate their suffering.

This tripartite model can certainly help explain the constellation of negative outcomes that victims of IBSA report. For instance, IBSA victims report elevated levels of anxiety, depression, PTSD, shame, and humiliation as well as a loss of trust, and sexual agency (Bates, 2017). Higher rates of somatic symptoms, such as headaches, and back pain, have also been reported by victims of IBSA (Ruvalcaba \& Eaton, 2020). Others have identified high suicide risk, with just under half of victims reporting having contemplated suicide (Bloom, 2014; Stroud, 2014). Further, Thomas (2018) notes that adolescent females in particular may lack the tools to navigate the desires, expectations, and pressures of sexting in general.

The bevy of negative outcomes associated with IBSA has sparked some insightful papers into the suffering and therapeutic processes that victims and clinicians may find helpful in navigating such a novel form of victimization. While DiTullio and Sullivan (2019) adopted a narrative approach to this, their focus is primarily to offer a guide to clinicians in how to navigate the complexity of IBSA with their clients. Although the current inquiry could serve a similar purpose, it is hoped that it will provide greater depth to the areas highlighted by the above authors while expanding the scope to include the role of the perpetrator and society, allowing for a more comprehensive framework for understanding. This has strong implications for how schools, lawmakers, media, and society as a whole can serve as catalysts for further suffering or resiliency through the stories and messages that they share. Ultimately, the goal of this paper is to help untangle this web so that victims of IBSA not only further understand themselves, but are able to see a way forward; a prelude to future stories.

\section{Victimization by the Perpetrator}

Most often when discussing victimization, we envision the direct harm caused by the perpetrator. This is a logical starting point in peeling back the layers of suffering that arise in the wake of IBSA. Narratology offers us a unique perspective in understanding these depths by exposing the mechanisms through which the suffering is inflicted. To do so, let us first consider the following story. Linde (2009) writes about an American insurance company that builds a sense of collective identity among its employees through a process called narrative induction. It begins with a story of the company's founder, whose story closely resembles the American dream of innovation, hard work, and success. A museum devoted to him is situated in corporate headquarters with photographs, possessions, and other work-related material on display with specific mention of how the items relate to the founder's story. The visual stimuli, paired with the story and the shared workplace all contribute to a collective identity, tying twenty-first century employees to their predecessors throughout the past century. Such a compelling and unifying experience would hardly take place if one were to visit the corporate museum and view only the Model A Ford on display without any commentary or context. This points to the power of the museum curator, who is able to create a story and evoke emotions using objects that are otherwise mundane or meaningless outside of their context. While this example is far tamer than what transpires during IBSA, the principles still apply. Namely, the opportunity for induction (by the subject) has been stripped away, leaving the victim isolated and quite literally on display, at the mercy of the perpetrator's rendition. Worse, the perpetrator is using women's own bodies as weapons against them, often for their own social gain (Clancy et al., 2020; McGlynn et al., 2020).

The idea of a jilted lover trying to get back at their former partner by fabricating or misrepresenting a story is not new, dating back several centuries (Konstan, 2006). However, the digital age has afforded us a greater number of means to do so, both in terms of content and in the audience (McCartan \& McAlister, 2012). Todorov (2003) admits that while images possess the power to transmit messages more clearly than words, they also have the power to disguise the truth. Unlike words, images lack a predicate telling the audience what they are viewing and what to think about it. We are then left to view these incredibly powerful, isolated photos with only our own predisposed evaluations and judgments to guide us. When a person non-consensually shares an intimate image that they have received with a third party, they truly are presenting a naked image. This does not refer to the content of the picture, rather that the image is shared completely devoid of context. Gone are the flirtatious back and forth messages that precipitated the photo or the intimate images that were reciprocated. So, too, are the images stripped of their emotional and personal value as they are anonymously posted online or sent to specific others as specimens, rather than expressions of sexual interest and trust. As Filipovic (2013) notes, the purpose of IBSA is to "shame, humiliate and destroy the lives and reputations of young women." In interviews with Bates (2015), one victim of IBSA described her experience as being stripped of their femininity, as her ex took pictures from unflattering angles to make her feel that she was not "doing a good job of being a woman" (p. 68). Thus, victims of IBSA are facing not only objectification and a very deep violation of their trust but also a decimation of their story. This may be why, when threatened with the release of her intimate images, actress Bella Thorne coordinated the release of the images herself. In controlling the release, Thorne was able to control the context and story (Webb, 2019). 
By presenting a distorted view into their collection of stories, the perpetrator deprives the victim of their own identity and creates their own narrative. This new narrative is then presented to third parties as a true portrayal of the victim. What makes stories so powerful is that they impel a person to accept the role that they are cast into. Frank (2010) succinctly describes the intensity and intimacy of stories when they write "people are embodied as much by stories as by their flesh" (p. 146). In cases of IBSA where the images (and the stories) have been disseminated among one's peers, this means that one is enveloped by stories that do not coincide with one's greater narrative. Several of the 75 IBSA victims interviewed by McGlynn et al. (2020) discussed these competing narratives, noting that their victimization resulted in an irreconcilable split between their past and present selves. The power of these images also means that the victim is limited in-if not completely deprived of-their ability to esteem themselves by putting forth a more accurate narrative, one of Ricœur's (2013) definitions of suffering. Indeed, this was also reflected in McGlynn et al. (2020) interviews. Undoubtedly, this contributes to the feelings of helplessness that are reported by victims of IBSA (Bates, 2017). One victim who recounted their experience commented it was as if "someone else had defined my destiny," (Bates, 2017, p. 31) perfectly encapsulating this sense of helplessness and loss of agency.

It is important not to gloss over the loss of trust that is reported by victims of IBSA and its implications. One participant in McGlynn et al. (2020) interviews reflected that their trust was "shattered on so many levels" (p. 14) while others found it difficult to trust men in general. Further, in addition to numerous accounts of struggles to trust future romantic partners, one victim of IBSA reported that she had trouble trusting co-workers at her new job, as her former partner had been a co-worker at her previous job (Bates, 2017). While trust has far reaching implications in the establishment and maintenance of healthy interpersonal relationships (Chua et al., 2009; Niven et al., 2012; Van de Rijt \& Buskens, 2006), Kristeva (2001) specifies that trust also serves an intrapersonal function. Specifically, Kristeva (2001) notes that promises are what help stabilize an otherwise unpredictable world. Both human action and the future have boundless capabilities, both positive and negative, and it is promises that give us a sense of security amidst this. DiTullio and Sullivan's (2019) own narrative exploration of IBSA emphasizes the importance of trust in understanding the depth of suffering and its central role in the healing process for individuals who have experienced this particular form of sexual violence.

Others have taken this idea further, claiming that trust is inseparable from one's being. Jaspers (1954) writes that when in love, among other things, we can become consumed by it, subordinating our own lives to it. In doing so, Jaspers argues, one's existence becomes the love or loyalty that one is experiencing or professes. The decision to subordinate ourselves, referred to as an unconditional imperative, is a decision borne out of lucidity, reflection, and freedom that is identical to our being. While a person who shares an intimate image of themselves with a romantic or sexual partner may not be encompassed by the same level of fervor that Jaspers was referring to, the principle still applies. The act of subordinating oneself, either partially or fully, is to make the self vulnerable, and is therefore an act of trust. If something were to undermine the trust (Jaspers prefers the term "power"), an emptiness arises that can only be escaped by re-establishing one's own sense of agency. Both Kristeva and Jaspers' accounts of trust imbue narratology, for they speak of an internal guidance system that provides clarity, safety, and purpose while holding tremendous power over the individual. When that trust is broken, the story that it creates is capable not only of disrupting one's inner library-a term Bayard (2007) uses to describe the stories most central to our being-but of providing a lens of distrust through which one views all existing and future experiences.

While it is outside the scope of the current paper, understanding the importance of narratives may also shed some light on perpetrators of IBSA. Frank (2010) argues that people often get so absorbed in their own stories that they are unable to comprehend how their actions impact the other characters and their own interpretation of the story. Can this explain the actions of a scorned lover who is so encompassed in their own pain that they disseminate intimate images of their former partner? Not entirely, as this would be a case of revenge porn, where the motive is implied in the term itself. Perhaps in the perpetrator's story, the wound they hope to inflict is singular and isolated, their own ignorance blinding them to the lasting impact this will have when told from the victim's perspective. Alternatively, do they intend to cause the victim lasting suffering because they feel that their own suffering is going to be prolonged as they struggle to make sense of their story? Another possibility is that the perpetrator is oblivious to or minimizes the extent of the harm and is motivated by their own gain, such as enhanced social status (Clancy et al., 2020). Neither partial explanation justifies the harmful behavior, but it does point to the power of stories - their ability to provide both clarity and confusion-in understanding the actions of those who engage in IBSA. Of course, different psychological and narratological inquiries may be necessary with regard to individuals who explicitly shame women on websites, group chats, and other forums dedicated to IBSA. 


\section{Victimization by Society}

When Parsons' mother posted about the ostracization her daughter faced by her friends and fellow students, she spoke to a larger and often overlooked component of IBSA: victimization by society. The social fallout that many victims of IBSA experience has its roots in developmental norms informed by cultural beliefs that are largely restrictive of women, particularly those who are unmarried or under the age of majority (Laumann et al., 2000; Phillips, 2018; Tolman, 1994). Clearly, there are also some basic narratological concepts at play which may help guide us in understanding the contributions that developmental and cultural psychology have to offer.

While stories individually help us make sense of our lives, Frank (2010) notes that our collection of stories also helps us understand new ones. That two people may interpret the same event differently is, in part, due to the collection of stories they have amassed. Where an individual files the new story is as important as the story itself, for its location influences what meaning, judgment, or value is associated with that story. In sum, the adjacent stories on this inner bookshelf of sorts help filter what information in the novel story is pertinent and helps spring forth the evaluations associated with them. As this process operates at the individual level, it also operates at the societal level, which makes novel stories such as IBSA particularly interesting. It also may help us understand why victims of IBSA have not experienced the empathic response that one would expect for someone who has had their sexual expression unwittingly shared with others.

For instance, there has been much outcry among academics and activists regarding the reluctance of elected representatives to take legislative action on IBSA (Brady, 2017; Burris, 2014; Kitchen, 2015). By and large, many of these elected officials (at least in the North American context) did not grow up in a digital age, nor have their constituents (Statistics Canada, 2019; U.S. Census Bureau, 2019). This undoubtedly influences their responses to IBSA. In particular, it shapes their responses to the sharing of intimate images or sexting in general, as it is less common-although not completely absent-among older adults than youth and young adults (Döring \& Mohseni, 2018). Not being part of their traditional dating scripts, the act of sending a nude image to a romantic or sexual partner is instead potentially placed among stories of risk-taking or lewd behavior. This filtration is so innate that its "deceptive transparency" (Frank, 2010, p. 56) convinces us that we are seeing things as they truly are, that we are truly objective observers of an unadulterated reality.

Viewed through this lens, it is the victim who initiated the series of events that lead to the non-consensual dissemination of their own image(s) by engaging in behavior that-according to certain individuals' accounts-is dangerous or even deviant. It does not help that research and media have framed sexting as a deviant or risky behavior rather than a valid expression of one's self (Hasinoff, 2015, 2016; Kosenko et al., 2017; Thurlow, 2017). Without any other experience, this framing may influence how select members of society respond to IBSA victims. Indeed, emerging evidence suggests that those who have never engaged in sexting hold victims of IBSA more responsible than those with sexting experience (Scott \& Gavin, 2017). Further, there is evidence that IBSA victims who send images to long-term partners are viewed as less blameworthy than those who initially sent a sexual image to a casual partner or romantic interest, suggesting not only traditional attitudes, but attitudes that may disproportionately impact sexual minorities, who engage in greater sexting behaviors (Garcia et al., 2016; Karaian \& Van Meyl, 2015; Rice et al., 2012; Setty, 2018).

For both Parsons and Logan, however, it was also their peers that bullied them. With one-fifth to one-quarter of high school students sending some form of sexual image to another (Englander, 2015; Strassberg et al., 2013), the idea of sexting is certainly more of a cultural norm among that demographic. While today's teens and young adults may have additional stories about sexual expression in a digital age that previous generations lack, that does not mean that these youth are bereft of the larger societal stories that exist, which reflect the instinctual selective and evaluative processes of their predecessors. As mentioned above, sexting has been framed as something to be protected from, with pressure on parents to discuss the consequences of such behavior with their children (again, with little attention paid to viewing this as a form of expression; Hasinoff, $2015,2016)$. This may contribute to the high rate of victim blaming attitudes among adolescents with respect to IBSA (deSHAME, 2017; Shariff, 2014). With more than one place to put this story, why do some youths opt to categorize it in the delinquent section? One possible answer is that stories interpellate the readers; that is, the reader is called upon to become immersed in the story and to take up the identity of the character. Doing so with respect to an individual who has just had their intimate images shared with others is a daunting undertaking, as one must accept one's own (potential) vulnerabilities in this regard. It may be much easier, or even intrinsic, to view the story more remotely and to join the chorus of others in condemnation.

Stories are also used to create boundaries. The ability to weave a coherent narrative means that our guidance system not only seeks for information to include, but also to exclude. When individuals become victims of IBSA, a new boundary is created, and a new means of assessment 
is afforded for those on the other side (Frank, 2010). If the judgment appears to be overwhelmingly negative, the victim's peers may opt not to cross the boundary and befriend them, lest they become the subject of similar ridicule. The victims are not blind to this development; one of the most prevalent themes in McGlynn et al. (2020) interviews was that of isolation from friends and even family as a result of their victimization. Whether it is the power of interpellation or concern over boundaries that is driving this behavior, both suggest that one's decision to scorn victims of IBSA is borne out of defensiveness rather than an intrinsic desire to cause harm. Support for similar protective mechanisms is found in the bevy of research on Just World Theory (Hafer \& Sutton, 2016).

To understand broader society's responses, we need to explore its collective inner library. With respect to sexual behavior, this is a particularly voluminous section, having been the subject of much debate over thousands of years. While it is accurate to conclude that sexting has been largely problematized in the Western world, a deeper exploration of sexual ethics is necessary (Döring, 2014; Hasinoff, 2015). Foucault (1990) notes that while the ancient Greeks certainly had more open attitudes toward sexual conduct than early Christians and modern Western cultures, what constituted appropriate behavior was still of much concern to Greek society. Reflecting on the ethics of sexual behavior as it was practiced by Greeks offers two advantages in understanding how modern society responds to IBSA. First, Greek ethics has had a considerable influence in how modern-day Western societies view, regulate, and punish behaviors (Cartledge, 2009; Fletcher, 1930; Nussbaum, 1994). Second, ancient Greek philosophy understood sexual ethics as being comprised of four unique domains, relating to its substance, use, mastery, and moderation, rather than lists of proscribed behaviors as defined by lawmakers or psychologists. While Foucault held the belief that culture in general is discontinuous, Richlin (1998) has put up a convincing rebuttal, as has Rozmarin (2005) in conceptualizing individuals as embodiments of the historical influences that have been placed upon them by outside institutions. Undoubtedly, the world has changed over the past 2,400 years. Yet, briefly diving into the four components of sexual ethics can still help enlighten our understanding of what victims of IBSA may experience, especially in the current climate where there are no uniform expectancies regarding the sending of sexual images in general, let alone their greater (non-consensual) dissemination.

With respect to the substance of sexual ethics, Greeks were not concerned with the specific behaviors or mechanisms involved in sexual acts-unlike many institutions today-but of the feelings of pleasure and desire that they evoked. Aphrodisia, then, was the dynamic relationship between pleasures, desires, and acts. Supposedly, the only offense one can commit in these regards is in their overindulgence (Aristotle, 1980). However, this is highly subjective, for what constitutes a moderate or permissible number of sexual images to be sent between consenting persons? To a person who has never sent such an image, either due to their own virtues or technological limitations, sending any images at all may seem like an excess. Contrarily, to a person who has either sent such images or is accustomed to this practice, what constitutes an excess may be a much higher number. Such division in expectations is reflected in Scott and Gavin's (2017) findings in which individuals with less sexting experience held victims of IBSA more responsible than those with more experience. Similarly, non-sexting college women interviewed by Ruvalcaba et al. (2020) reported holding negative attitudes toward their sexting counterparts and had low levels of support for victims of IBSA, with only $5 \%$ of the sample mentioning having empathy or pity for the person.

Throughout Greek history, there was also concern about the position that one played during sexual acts. Coinciding with their greater autonomy, men held active roles, while women, slaves, and young boys assumed their passive counterparts. Disruption of this binary, which is still reflected today, was cause for alarm and beratement of the affected parties (Aristotle, 1936; Foucault, 1990). A similar chastisement of women for being sexually agentic has continued into modernity and its more common verbiage "slut shaming" has been the subject of extensive review (see Tanenbaum, 2015; van Royen et al., 2018, for reviews). Youth are aware, at least implicitly, of these expectations. In focus groups with high school students, Dobson (2019) found that girls reported having to engage in strict sexual regulation, lest they be labelled a "slut." This concern is not unwarranted, as most (65\%) non-sexting females interviewed by Ruvalcaba et al. (2020) viewed females who sext as attention seekers, with only $7 \%$ indicating that women may do so for self-positive reasons (such as body positivity). With respect to the dissemination of images, those who hold more traditional gender attitudes ascribe more promiscuity and responsibility to victims of IBSA than those who hold more modern attitudes (Mckinlay \& Lavis, 2020). This is promising, although participant still attributed a moderate amount of blame to the victim.

There is also emerging evidence that responses to sexting and the subsequent dissemination of intimate images is more complex than binary contrasts between sexters and non-sexters. Mckinlay and Lavis (2020) reported that females were judged more harshly depending on the degree of nudity in the photo, with those who took topless photos being seen as more blameworthy when the image was non-consensually disseminated than those who had taken a picture wearing lingerie. Similarly, in a mock jury paradigm involving IBSA between two ex-partners, female IBSA victims were attributed more blame for their victimization than men when the intimate image was 
initially created by the victim and shared with their then-partner (Uhl, 2017). It is not surprising, then, that young women in particular report struggling to navigate these uncharted waters, where women's (gradually) increasing sexual freedoms collide with a traditional, misogynistic regulation of women which is so deeply entrenched that one would blame a teenage woman for her own victimization (Dobson, 2019; Setty, 2019; Thomas et al., 2017). Bay-Cheng (2015) explores this further in their own proposal, positing that women are trapped in a matrix of increasing sexual agency that operates in a society still dominated by gendered sexual norms. Muddying the sexting waters further is the consistent finding that many women (especially young women) are pressured by men to send sexual images, suggesting that sexting is not always an agentic act by the woman but rather follows a script that is steeped in misogyny (Englander, 2015; Lumsden \& Morgan, 2012; Reed et al., 2017).

The disruption associated with women becoming agentic sexual beings (and even when they aren't) also has implications for the second component of Foucault's sexual ethics, chrēsis, which relates to need. Specifically, an ethical being was one whose sexual behaviors met their sexual needs without overabundance or diminishing future sexual desire. Here again we see chrēsis's relation to the modern era, as one of the primary motives of sending sexual images is to evoke desire and thus, increasing need (at least temporarily). Further, men have largely followed older sexual scripts about being the pursuer, more frequently requesting sexual images from women than vice-versa (Salter et al., 2013; Strassberg et al., 2013). Others have noted that young men are presented in the media as inherently unable to practice sexting in a respectful, controlled manner (Herriot \& Hiseler, 2015). This places the woman (again) in the role of the gatekeeper, unfairly putting the responsibility on them to ensure that men do not overindulge sexually. By sending a sexual image, which may also be viewed multiple times and thus contribute to excess, the modern-day woman could be seen as abandoning their historical duty of protecting men from their own moral demise. If so, they would be assuming the same blame that was levied against the internet pornography in the early 2000s, which some commentators accused of "grooming" men (Dines, 2011; Eberstadt \& Layden, 2010; Whisnant, 2010, p. 114).

The final two domains of sexual ethics, enkrateia and sōphrosyne $\bar{e}$, refer to self-mastery and moderation, respectively. Enkrateia was borne out of the concern that Greeks had over the power of sexual energy and its potential to make one overindulge. Once a person mastered the self-control that allowed oneself to be continent, were they ready to be moderate. This state, sōphrosyne, was considered by Aristotle to be one of virtue and freedom and one that was seen as a highstatus endeavor (Plato, 1974). Thus, while characterized as an internal struggle, women who relinquish their traditional sexual gatekeeping roles-let alone women who exert external pressure or desire by sexting - are seen as jeopardizing a lifelong endeavour and robbing men of reaching a supposedly blissful state.

There are, of course, other reasons why society vilifies victims of IBSA that do not require a strong comprehension of Greek philosophy. Returning to Frank (2010), it is argued that we have become so familiar with stories and so adept at telling them that we have an ability to sense how a story should end. These predictable plot completions, like all narrative components, are influenced by the stories we've heard as well as the context in which they occur. Like one is able to predict that two jilted lovers will reconcile at the end of a romantic comedy, so too are we able to complete less scripted events. When news stories mention that a female had sent sexual images to a romantic or sexual partner, it is ostensibly easy to complete the story of having those same photos be shared beyond the intended recipient. Of course, this is an incredibly biased view of the event—clearly something significant happened if it is being mentioned in the evening news, which also provides contextual information to help complete the story. However, our predictable plot completions come so naturally that it is easy to turn on the victim for their inability to foresee the outcome (Guilbault et al., 2004).

While this is not identical to hindsight bias, when predictable plot completions do indeed materialize, it further strengthens the association and could potentially lead to more victim blaming, as has been found in other studies looking exclusively at hindsight bias (Malle et al., 2014). For instance, victims in sexual assault vignettes were attributed more blame for the attack than in identical vignettes in which no outcome is mentioned (Felson \& Palmore, 2018). In another study, participants were presented with an ambiguous vignette and divided into a foresight and hindsight condition (Marchal et al., 2013). Those in the foresight condition were asked to rate the likelihood of a number of different outcomes, while those in the hindsight condition were provided an additional vignette which noted that the female character was sexually assaulted by a co-worker. In confirmation of hindsight bias, those who were presented with the outcome reported higher likelihoods of sexual assault than those in the foresight condition. Whether predictable plot completions and hindsight bias contribute to some of the negative public reactions that IBSA victims face has not yet been examined, but given the responses victims of other sexual crimes elicit, it is a plausible and worthwhile line of inquiry.

\section{Victimization by the Self}

The opening of Frank's book (2010) notes the importance of stories in making sense of one's world. The implied message here is that without familiar, sensible narratives, 
understanding the world in which we live would be a near impossibility and attempts to do so would lead to great discomfort and confusion. Thus, we not only need stories, but efficient means of organizing them, what Bayard (2007) called the inner library. This library houses the narrative habitus, the collection of stories that provide us with an understanding of ourselves. That we are naturally drawn to stories which align to our understanding of the self, and therefore, withdraw from those that do not is the work of this habitus. Both the inner library and its narrative habitus influence how we interpret new stories. The organization of such an immense library is often a seamless operation, with new stories added to the shelves next to others that are alike in characters, narrative, or moral value. Having these guideposts not only makes the new story easier to place, it also helps give them meaning, context, and resonance.

But what happens when a story is presented that does not have a preordained place on the shelf? Frank (2010) argues that we are predisposed against adding new sections to our library and seek to disregard stories that do not fit with the themes already present. For instance, the athlete who has weathered failure on their route to victory may more readily accept and integrate future failures into their narratives than the athlete who has known only success. When the story is inconsequential, this is an effective strategy. However, individuals who are suddenly cast as victims of IBSA are not afforded such a convenient means of escape; this new story is far too personal to be omitted from their library. Distress can occur here in a number of ways. First, there is the existential struggle of accommodating a new, discordant story into one's inner library. Given the function of the inner library in making sense of the world, such a fundamental change can result in a change in the way one perceives the world. This is reflected in the interviews conducted by Bates (2017) and McGlynn et al. (2020) on women who have experienced IBSA who expressed difficulty trusting the intentions of others, as their actions were viewed with more suspicion.

It was discussed previously the feelings of betrayal and loss of trust that are often reported by victims of IBSA. So, too, were the direct harms the perpetrator causes the victim when they share and re-story a private image. However, there are also more longitudinal, circuitous harms that can be inflicted, particularly when the images are shared with the victim's peers. It is safe to assume that when one engages in IBSA - especially if the distribution is to people known to the victim - the intention is to create a negative portrayal (or story) of the victim that is largely contradictory to how the victim imagines themselves. What follows is a potential disconnect between how one views oneself and how others view them. What concerns us here is how this discord between one's understanding of self and others' evaluations could undermine the harmony one has with oneself. Indeed, this was a common theme among interviews with IBSA victims, who reported that both others and even they themselves viewed them differently after the abuse (McGlynn et al., 2020). This expression of self-blame is unfortunate, but not entirely surprising. As noted above, victim blaming attitudes with respect to IBSA are highly prevalent and may have even been previously endorsed by a current victim (deSHAME, 2017; Shariff, 2014). Qualitative studies that have explored perceptions of blame among adolescents have also found that victims are ascribed responsibility for their victimization (Dobson \& Ringrose, 2016; Lippman \& Campbell, 2014).

Recently, Mandau (2020) collected 182 posts written by adolescent females on a Danish counselling hotline website (BørneTelefonen) that described their experience of IBSA victimization. Analysis revealed that self-blame was one of the most frequent and consistent themes that emerged in the posts, surpassed only by comments expressing fear and worry about the (further) circulation of the images and telling their parents. Just under one-third of posts contained self-blaming language, with Mandau (2020) reflecting that the girls demonstrated a pattern of "turning inwards" (p. 9) rather than expressing anger or desire for retribution, the latter only being present in roughly one in ten posts. Selfblame was most commonly expressed by referring to oneself or their actions as stupid or naïve, while others were more direct, with one 14-year-old poster commenting "deep down inside, I know that it's my own fault. It was me who chose to trust him and send the picture" (p. 10). A 12-year-old poster linked their self blame to feelings of isolation, noting that "I don't feel like I can talk to anyone about it, since it's my own fault" (p. 11). These self-blaming beliefs also emerged in McGlynn et al's (2020) interviews with adult women. Like in Mandau (2020), references to oneself as being "stupid" for having sent an image or trusted the person emerged. Other feelings of embarrassment, shame, and disgust with oneself were also noted. Taken together, this emerging line of work suggests that self-blame is prevalent among female victims of IBSA, which coincides with decades of work on sexual assault victims (Kline et al., 2018; Miller et al., 2010; Ullman, 1996).

It has been noted above that stories inherently create boundaries. This was discussed from a societal perspective, where the victim was seen as a pariah whom others did not want to join. However, the boundary is also a personal matter, as evidenced by victims' reports of a personal division of into pre- and post-victimization selves (McGlynn et al., 2020). The novelty of IBSA means that its victimization cannot be likened to any other experience, isolating the victim in their suffering. Even a well-meaning friend who breaks the societal boundary struggles to transcend the personal one. As one victim reported, despite the good intentions of their friends and family, they were just unable to understand that type of abuse (Bates, 2017). Such isolation, the divergence 
between the self and others, is one of the axes of suffering identified by Ricœur (2013). Based on their framework, victims who suffer in this realm are prone to view others as extending the suffering, ostensibly by not understanding. Simultaneously, the victim directs the blame inward, chastising themselves for the circumstances that they currently find themselves in a further example of self-blame. As one 14-year-old victim who had been ostracized and belittled by her school peers later recalled "I just assumed it was my fault for being a slut" (Brennan, 2016).

While each of these three routes of victimization can or will apply to varying degrees for each person, it is important to note in this section that not all people who experience IBSA will necessarily label themselves as a "victim." Much like the broader sexual violence literature, many who have experienced such violence prefer to identify as "survivors" (Arielle, 2016; Jordan, 2013; Spry, 1995). This shifts the narrative, positioning oneself as an active subject and potentially putting an end to one of Ricœur's (2013) forms of suffering. Indeed, there is some evidence that those who use the "survivor" label after experiencing sexual violence experience less depressive and PTSD symptoms (Boyle \& Clay-Warner, 2018).

\section{Victimized by a True "Dark Triad": the Dynamics of the Perpetrator, Society, and Self}

It would be foolhardy to attempt to capture the self-victimization that occurs without mentioning the contributions of the perpetrator and society. In fact, it is this network that may contribute to the immense suffering associated with IBSA. That the selective and evaluative processes of one's internal guidance system are influenced by larger sociocultural elements has already been discussed; however, the relationship that perpetuates suffering has not yet been examined. Liben's (2017) constructivistecological perspective of gender development is particularly salient in understanding how the various facets of sexual ethics outlined above play out in the relationship between the self, the offense, and society. It builds upon Liben's previous work on developmental intergroup theory, which sought to identify the catalysts behind the formation, maintenance, and modification of children's group stereotypes (Bigler \& Liben, 2006, 2007). Her most recent endeavor is comprised of two complementary elements encompassing individual and sociocultural characteristics that influence the relationship between an individual and their environment. At the individual level, a person's previous experiences, beliefs, and values influence what aspects of their environment they engage with and how that information is stored and retrieved. With respect to gendered stereotypes, Liben proposes a model that hinges on the degree to which a person endorses a culture's gender stereotypes, the person's own interests, and whether the person views the world through a gendered lens (Blakemore et al., 2009; Liben \& Bigler, 2002). Much like Frank's (2010) idea of an internal guidance system, both concepts reflect the filtering and subsequent judgment of information based on relevant personal and social narratives.

The sociocultural element is more expansive, revealing the values and traditions held by society, institutions, and other powerful figures which often form the foundation on which the individual processes exist and serve as the setting in which a person is immersed. While multiple stereotypes may be perpetuated in any culture, Liben (2017) argues that gender is perhaps the most salient, noting that it is often easy to differentiate persons of different genders, that activities are often explicitly labelled as gender-specific, and that gender portrayals of specific actions are often over- or underrepresented. With multiple mechanisms highlighting the importance of gender, the accompanying rules, beliefs, and expectations that society attaches to it are also emphasized. With respect to gendered sexual expectations, media messages can be particularly reflective of these sociocultural attitudes. For instance, an analysis of 130 scenes across 34 films found that the scenes conveyed three messages with respect to teenage girls' sexual desire: that desire was to go unspoken, that "bad girls" display their desire, and that those who do express desire face negative consequences as a result (Smith, 2012). This was largely reflected in interviews by Ruvalcaba et al. (2020), where non-sexting women attributed other women's motivations for sexting to negative reasons, which differed considerably from sexting women's self-reported motivations for their own behavior.

Such messages appear in other media as well; an analysis of over 150 articles in U.S. girl's magazines found evidence of a sexual double standard, with boys' sexual desire being covered more extensively than girls' while girls were more often represented in stories of sexual risks and other potential negative outcomes (Joshi et al., 2011). While Thompson et al. (2020) recently emphasized the implicit nature of sexual double standards, with respect to sexting, the sexual double-standard has not gone unnoticed. In 41 interviews with youth aged 14-18, Setty (2019) noted that sexting was associated with agency and legitimacy for young men but not for young women, who were disempowered and assumed the burden of managing the risks of sexting. Focus groups conducted by Meyer (2016) and Ricciardelli and Adorjan (2019) evoked similar responses. For instance, participants noted that unlike men, women have "something to lose" (p. 57) if a sexual image is disseminated beyond the intended audience. Another participant concluded that society effectively shamed female sexual desire. Similar sexual double standards have been reported been reported with other samples as well (e.g., Lim et al., 2016; Liong \& Cheg, 2017; Van Ouytsel et al., 2017). In effect, such salient ideals of female sexual 
expression (or lack thereof) act as a large volume, if not collection, in one's inner library, against which their action are evaluated.

This is also reflected in Thomas et al. (2017) analysis of teen's online stories of potential wrongdoing. With respect to sex, female adolescents were more likely than their male counterparts to discuss concerns about whether having sex, wanting sex, and sending nude photographs is appropriate. That the teenage girl in Brennan's (2016) review of IBSA stories referred to herself as a "slut" is not a chance occurrence. Rather, she is viewing herself through her interpretation of sociocultural norms, which predate having engaged in sexting behavior. Had she not reached this conclusion herself, she only has to look outward to see the examples of "ideal femininity" that society would unfavorably compare her to, much like victims of sexual assault have reported (Abrams et al., 2003; Smith, 2012; Weiss, 2010). Thus, victims of IBSA not only face the struggle of incorporating their victimization story into their inner libraries, but they also have to juggle the judgmental narratives that members of the public force onto their shelves.

This is particularly problematic for female youth who are afforded even less sexual freedom than their already restricted adult counterparts (Buchanan, 2007; Liben, 2017; Penney, 2016). In one jurisdiction in the USA, the local district attorney threatened to charge several teenage women with child pornography charges for possessing nude photos of themselves unless they completed a six- to nine-month program to "understand how their actions were wrong" and "gain an understanding of what it means to be a girl in today's society" (Miller v. Skumanick, 2009). Expected to demonstrate purity or virginity, young female victims of IBSA are not only chastised for breaking these misogynistic standards but are forever barred from reaching those ideals now that their sexual expression has been exposed. Penney (2016) notes this in their analysis on the media coverage of Todd's death, claiming that they were "preoccupied" with her topless photo, juxtaposing it against a backdrop in which they tried to contain young female sexuality. Similar expectations are also invoked in Jaspers' (1954) musings. Here, the unconditional imperative is judged by the person in its moral, ethical, and metaphysical links to evil. While this appears to be an intrinsic judgment, several mentions of purity and "sensual impulses" are mentioned, which undoubtedly invokes broader societal influences not only in how purity is defined but in the value that is afforded to it. Thus, not only does society devalue women for being sexually agentic, there is also an opportunity for their relations to be evaluated along an axis of evil.

Frank (2010) notes that our inner libraries are not only used to make sense of the world, but to protect and restore ourselves from adversity, particularly when the hardship is generated by outside forces. It is at these moments where a person is trying to preserve their dignity and self-assurance that the power of stories and the stakes that rely on them are the greatest. Enveloped in sociocultural stories that romanticize female sexual restraint, it is easy for women to see themselves as the ones who have faltered. Comments made by Australian federal police assistant commissioner Shane Connelly to an IBSA inquiry calling on victims to "grow up" and equating having one's intimate images publicly shared to "catch[ing] a virus" not only contribute to these narratives but also demonstrate to women that the legal system is uninterested in their circumstances (Australian Associated Press, 2016). Others have claimed that police have openly laughed at them when they reported it (Daily Telegraph Australia, 2020). In the UK, one police officer is currently undergoing an internal investigation after they used information filed in a police report to contact a victim of IBSA to request nude photographs (Nsubuga, 2020).

That legislation criminalizing IBSA is only recently being heard not only reflects slow-changing societal attitudes-which has been described as too "shrill," in the case of youth sexuality, to even be discussed (Rollins, 2011) but also serves to disempower victims who were helpless to prevent their intimate images from being disseminated. Conceptualized by Henry and Powell (2015) as "institutionalized harm," the reduction in victim agency is also another of Ricœur's (2013) forms of suffering. Viewed through this lens, IBSA victims are restrained from participating in their own life, unable to direct it, which makes them prone to the direction of others. They are at the mercy of ingrained societal practices regulating sexual behavior that have only been seriously challenged in the past few decades. Regardless of whether the victim turns outward or inward, they are faced with an impeded ability to create their own narrative, a paralysis that is always looming as the images could resurface at any given moment, threatening whatever narrative the victim was eventually able to construct. Indeed, many victims of IBSA describe their abuse as ongoing, experiencing daily fear that the images will re-emerge and distress that they are unable to ensure that the images are permanently deleted (McGlynn et al., 2020). Thus, there is a risk that victims of IBSA will become immersed in a circuitous course of self-blame as sociocultural narratives are offered to fill the voids in one's inner library which then shape the stories that one creates themselves.

That society and, as a result, our legal system, has been resistant to side with the victim has implications that extend beyond the current stories being told. A narrative view of ethics holds that our values and conscience are tied to the stories that we draw upon. These stories are used to reinforce principles and the rules in which they operate. If the stories that surround IBSA are largely victim-blaming, slut-shaming, or are embedded within misogyny, then there is no roadblock, no point of moral reflection, for the person inclined 
to non-consensually share intimate images of another being. This is to say nothing of the forums that openly endorse the redistribution of sexual images and the ethical green-lighting that accompanies it. The recent wave of IBSA legislation (Citron \& Franks, 2014; Henry \& Powell, 2016) taking hold across the Western world is welcome then, if not delayed, as it may serve as the strongest among a weak cast of deterrents in the dissemination of another's intimate images. However, recent issues regarding low prosecution rates and poor legal framing may weaken this deterrent effect (e.g., Dodge, 2020; Ellison, 2018; Humbach, 2014).

\section{Narratives Love Company}

Experiencing sexual violence in general has been phenomenologically explored as a disruption in one's place in the world (Brison, 2003; Vera-Gray \& Fileborn, 2018). Given that we use stories to make sense of our world, so too it makes sense for us to have used narratology to unravel the complex, dynamic array of elements that are present in the suffering of IBSA victims. Much has been said about the power of narratives in shaping and clarifying our lives, but the ability to narrate one's own story-arguably its most important function-has not yet been discussed. Understandably, there will be times when this is impossible, whether by the paralysis of thought (see Arendt, 2003) or suffering (see Ricœur, 2013). It was also mentioned earlier that IBSA is the perpetrator's retelling of a story, one designed to demean the victim, and how pervasive that story can be. However, there is still space for the victim to reshape both the story surrounding the image and the story of their own victimization in a way that helps to restore their dignity and foster a greater understanding of themselves. Bayard (2007) claims that doing so is an inevitability, while Arendt (2003) notes that "you always need at least two tones to produce a harmonious sound" (p. 183). In DiTullio and Sullivan's (2019) own narrative inquiry into the experience of IBSA, they highlight the necessity of reauthoring such instances as a precursor to re-establishing trust in oneself. Ricœur (2013) would also likely see reframing as an act of authority against one's own suffering. Both Chambers and Chiarini understood the importance of adding their voice to the story, not only for themselves, but for others as well, as IBSA is also a social victimization which impacts the ability of women to safely navigate the digital world and their place in it (Yar \& Drew, 2019). Their stories became instrumental in the development of IBSA legislation in their jurisdictions. Through their advocacy, legal sources of suffering are slowly eroding. That they can emerge from victimhood as champions is of immeasurable importance to the stories that we as a society tell. As more victims come forward, as more stories are told, a narrative shift takes place in our inner libraries that is fundamental to the healing of IBSA victims and the collective emancipation of women. It is hoped that the untangling offered in this narrative exploration is able to inspire the same.

With respect to clinical practice, the use of this socionarratological approach in untangling the complex web of personal, peer, and societal is apparent. While clinicians are likely quite familiar with treating many of the outcomes reported by victims of IBSA, such as depression, anxiety, PTSD, and suicidal ideation (Bates, 2017), the jumbled and interconnected array of factors that underlie them may be quite novel. In exploring their nature and relation, they are exposed, allowing a clinician and their client to identify the unique constellation and valence that is contributing to their suffering. The contribution of this paper, however, is not exclusively tied to the reactive realm; there are also proactive implications, particularly as they relate to framing. The contribution of risky sexting narratives purported by both researchers and the media (as discussed above) can be quite problematic for people who have experienced IBSA-particularly youth. The goal, then, is similar to the efforts that victim advocates of sexual violence have been targeting for decades. We must work toward creating a narrative in which female sexual agency is not only legitimized, but respected. Doing so not only opens up opportunities for healing, but also makes it more difficult for perpetrators to weaponize women's bodies. With new forms of violence emerging, it is essential that this fight continues its momentum, lest one more person fall suffer at the hands of IBSA.

\section{Declarations}

Ethical Approval Given the theoretical nature of this paper, institutional ethical review was not necessary, as per Article 2.1 of the Government of Canada's Tri-Council Policy Statement (TCPS-2). However, care was taken when preparing the manuscript to ensure that those who have experienced image-based sexual abuse were presented in a way that was respectful, as suggested by the TCPS- 2 .

Conflict of Interest The author declares no competing interests.

\section{References}

Abrams, D., Viki, G. T., Masser, B., \& Bohner, G. (2003). Perceptions of stranger and acquaintance rape: The role of benevolent and hostile sexism in victim blame and rape proclivity. Journal of Personality and Social Psychology, 84(1), 111-125.

Arendt, H. (2003). Responsibility and judgment. Random House.

Arielle, R. (2016). Beyond the binaries: Exclusive dichotomies in the anti sexual violence movement. In J. Patterson (Ed.), Queering Sexual Violence (pp. 39-48). Magnus Imprint.

Aristotle. (1936). Problems (W. S. Hett, Ed. and Trans.). Loeb Classical Library. 
Aristotle. (1980). Nicomachean Ethics (D. Ross, Rev. J. L. Ackrill, \& J. O. Urmson, Trans.). Oxford University Press.

Australian Associated Press. (2016, February 18). 'Grow up' and stop taking naked photos of yourself, police tell revenge porn inquiry. The Guardian.

Bates, S. L. (2015). "Stripped": An analysis of revenge porn victims' lives after victimization (doctoral dissertation). Simon Fraser University.

Bates, S. (2017). Revenge porn and mental health: A qualitative analysis of the mental health effects of revenge porn on female survivors. Feminist Criminology, 12(1), 22-42.

Bay-Cheng, L. Y. (2015). Living in metaphors, trapped in a matrix: The ramifications of neoliberal ideology for young women's sexuality. Sex Roles, 73(7), 332-339.

Bayard, P. (2007). How to talk about books you haven't read. Bloomsbury Publishing USA.

BBC. (2018). Chrissy Chambers: Revenge porn almost killed me. Retrieved from https://www.bbc.com/news/technology-42733034

Benotsch, E. G., Snipes, D. J., Martin, A. M., \& Bull, S. S. (2013). Sexting, substance use, and sexual risk behavior in young adults. Journal of Adolescent Health, 52(3), 307-313.

Bigler, R. S., \& Liben, L. S. (2006). A developmental intergroup theory of social stereotypes and prejudice. In R. V. Kail (Ed.), Advances in Child Development and Behavior. (Vol. 34, pp. 39-89). Elsevier.

Bigler, R. S., \& Liben, L. S. (2007). Developmental intergroup theory: Explaining and reducing children's social stereotyping and prejudice. Current Directions in Psychological Science, 16(3), 162-166.

Blakemore, J. E. O., Berenbaum, S. A., \& Liben, L. S. (2009). Gender development. Taylor \& Francis.

Bloom, S. (2014). No vengeance for revenge porn victims: Unraveling why this latest female-centric, intimate-partner offense is still legal, and why we should criminalize it. Fordham Urban. Law Journal, 42, 233-289.

Borrajo, E., Gámez-Guadix, M., \& Calvete, E. (2015). Cyber dating abuse: Prevalence, context and relationship with offline dating aggression. Psychological Reports: Relationships and Communications, 116, 565-585.

Boyle, K. M., \& Clay-Warner, J. (2018). Shameful "victims" and angry "survivors": Emotion, mental health, and labeling sexual assault. Violence and Victims, 33(3), 436-452.

Brady, K. M. (2017). Revenge in modern times: The necessity of a federal law criminalizing revenge porn. Hastings Women's Law Journal, 28(1), 3-24.

Branch, K., Hillinski-Rosick, C. M., Johnson, E., \& Solano, G. (2017). Revenge porn victimization of college students in the United States: An exploratory analysis. International Journal of Cyber Criminology, 11(1), 128-142.

Brennan, S. (2016, October 21). 'I was ostracized and ridiculed and it made me suicidal': Victims of revenge porn reveal how they felt after their intimate photos were leaked. Daily Mail.

Brison, S. J. (2003). Beauvoir and feminism: Interview and reflections. In C. Card (Ed.), The Cambridge Companion to Simone de Beauvoir (pp. 189-207). Cambridge University Press.

Brown, S. (2006). Integration by way of the criminology of hybrids. In G. Barak (Ed.), Criminology: An integrated approach (pp. 118-121). Rowman \& Littlefield.

Buchanan, K. S. (2007). Lawrence v. Geduldig: Regulating women's sexuality. Emory Law Journal, 56(4), 1235-1303.

Burkett, M. (2015). Sex(t) talk: A qualitative analysis of young adults' negotiations of the pleasures and perils of sexting. Sexuality \& Culture, 19(4), 835-863.

Burris, A. (2014). Hell hath no fury like a woman porned: Revenge porn and the need for a federal nonconsensual pornography statute. Florida Law Review, 66, 2325-2359.
Cartledge, P. (2009). Ancient Greek political thought in practice. Cambridge University Press.

Casper, M., \& Moore, L. J. (2009). Missing bodies: The politics of visibility (Vol. 2). New York University Press.

Celizic, M. (2009, March 6). Her teen committed suicide over 'sexting.' Today.

Chiarini, A. (2013). I was a victim of revenge porn. I don't want anyone else to face this. Retrieved from https://www.theguardian.com/ commentisfree/2013/nov/19/revenge-porn-victim-marylandlaw-change

Chua, R. Y., Morris, M. W., \& Ingram, P. (2009). Guanxi vs networking: Distinctive configurations of affect-and cognition-based trust in the networks of Chinese vs American managers. Journal of International Business Studies, 40(3), 490-508.

Citron, D. K., \& Franks, M. A. (2014). Criminalizing revenge porn. Wake Forest Law Review, 49, 345-392.

Clancy, E. M., Klettke, B., Hallford, D. J., Crossman, A. M., Maas, M. K., \& Toumbourou, J. W. (2020). Sharing is not always caring: Understanding motivations and behavioural associations with sext dissemination. Computers in Human Behavior, 112, advance online copy.

Daily Telegraph Australia. (2020, February 28). A 21 year-old revenge porn victim paralysed by anxiety says police ridiculed and laughed at her. Author.

DeKeseredy, W. S., \& Schwartz, M. D. (2016). Thinking sociologically about image-based sexual abuse: The contribution of male peer support theory. Sexualization, Media, \& Society, 2(4), 1-8.

deSHAME. (2017). Young people's experiences of online sexual harassment: A cross-country report from Project deSHAME. Retrieved from https://www.childnet.com/ufiles/Project_ deSHAME_Dec_2017_Report.pdf

Dines, G. (2011, May 17). How the hardcore porn industry is ruining young men's lives. Newcastle Star.

DiTullio, M. C., \& Sullivan, M. M. (2019). A feminist-informed narrative approach: Treating clients who have experienced imagebased sexual abuse. Journal of Feminist Family Therapy, 31(2-3), $100-113$.

Dobson, A. S. (2019). 'The things you didn't do': Gender, slut-shaming, and the need to address sexual harassment in narrative resources responding to sexting and cyberbullying. In $\mathrm{H}$. Vandebosch \& L. Green (Eds.), Narratives in research and interventions on cyberbullying among young people (pp. 147-160). Springer.

Dobson, A. S., \& Ringrose, J. (2016). Sext education: Pedagogies of sex, gender and shame in the schoolyards of tagged and exposed. Sex Education, 16(1), 8-21.

Dodge, A. (2020). Trading nudes like hockey cards: Exploring the diversity of 'revenge porn' cases responded to in law. Social \& Legal Studies, advance online publication.

Döring, N. (2014). Consensual sexting among adolescents: Risk prevention through abstinence education or safer sexting? Journal of Psychosocial Research on Cyberspace, 8(1), 1-9.

Döring, N., \& Mohseni, M. R. (2018). Are online sexual activities and sexting good for adults' sexual well-being? Results from a national online survey. International Journal of Sexual Health, 30(3), 250-263.

Eaton, A. A., \& McGlynn, C. (2020). The psychology of nonconsensual porn: Understanding and addressing a growing form of sexual violence. Policy Insights from the Behavioral and Brain Sciences, 7(2), 190-197.

Eberstadt, M., \& Layden, M. A. (2010). The social costs of pornography: A statement of findings and recommendations. Witherspoon Institute.

Ellison, M. (2018, March 6). Less than half revenge porn cases passed to prosecutors. BBC News. https://www.bbc.com/news/uk-scotland42689607 
Englander E. K. (2015). Coerced sexting and revenge porn among teens. Bullying, Teen Aggression \& Social Media (March/April), 19-21.

Felson, R. B., \& Palmore, C. (2018). Biases in blaming victims of rape and other crime. Psychology of Violence, 8(3), 390-399.

Filipovic, J. (2013, Jan. 28). 'Revenge porn' is about degrading women sexually and professionally. The Guardian. https://www. theguardian.com/commentisfree/2013/jan/28/revenge-porndegrades-women

Fletcher, R. V. (1930). The influence of Greece upon our modern life. The Classical Journal, 25(6), 422-432.

Foucault, M. (1990). The use of pleasure: Volume 2 of the history of sexuality (R. Hurley, Trans.). Vintage Books.

Frank, A. W. (2010). Letting stories breathe: A socio-narratology. University of Chicago Press.

Garcia, J. R., Gesselman, A. N., Siliman, S. A., Perry, B. L., Coe, K., \& Fisher, H. E. (2016). Sexting among singles in the USA: Prevalence of sending, receiving, and sharing sexual messages and images. Sexual Health, 13(5), 428-435.

Guilbault, R. L., Bryant, F. B., Brockway, J. H., \& Posavac, E. J. (2004). A meta-analysis of research on hindsight bias. Basic and Applied Social Psychology, 26(2-3), 103-117.

Hafer, C. L., \& Sutton, R. (2016). Belief in a just world. In C. Sabbagh \& M. Schmitt (Eds.), Handbook of social justice theory and research (pp. 145-160). Springer.

Hasinoff, U. (2015). Sexting panic: Rethinking criminalization, privacy and consent. University of Illinois Press.

Hasinoff, A. A. (2016). How to have great sext: Consent advice in online sexting tips. Communication and Critical/Cultural Studies, 13(1), 58-74.

Henderson, L., \& Morgan, E. (2011). Sexting and sexual relationships among teens and young adults. McNair Scholars Research Journal, 7(1), 31-39.

Henry, N., McGlynn, C., Flynn, A., Johnson, K., Powell, A., \& Scott, A. (2020). Image-Based Sexual Abuse: a study on the causes and consequences of non-consensual nude or sexual imagery. Routledge.

Henry, N., \& Powell, A. (2015). Embodied harms: Gender, shame, and technology-facilitated sexual violence. Violence Against Women, 21(6), 758-779.

Henry, N., \& Powell, A. (2016). Sexual violence in the digital age: The scope and limits of criminal law. Social \& Legal Studies, 25(4), 397-418.

Henry, N., Powell, A. and Flynn, A. (2017), 'Not just 'revenge pornography': Australians' experiences of image-based abuse. A summary report. RMIT University.

Herriot, L., \& Hiseler, L. E. (2015). Documentaries on the sexualization of girls: Examining slut-shaming, victim-blaming and what's being left off-screen. In E. Renold, J. Ringrose, \& R. D. Egan (Eds.), Children, sexuality and sexualization (pp. 289-304). Palgrave Macmillan.

Hinduja, S., \& Patchin, J. W. (2010). Sexting: A brief guide for educators and parents. Retrieved from http://www.cyberbullying.us/ Sexting_Fact_Sheet.pdf

Humbach, J. A. (2014). The Constitution and revenge porn. Pace Law Review, 35(1), 215-260.

Huntley, R. (2012). Amanda Todd - transcript of video. Pastebin.

Jordan, J. (2013). From victim to survivor-and from survivor to victim: Reconceptualising the survivor journey. Sexual Abuse in Australia and New Zealand, 5(2), 48-56.

Jaspers, K. (1954). Way to wisdom: An introduction to philosophy. Yale University Press.

Joshi, S. P., Peter, J., \& Valkenburg, P. M. (2011). Scripts of sexual desire and danger in US and Dutch teen girl magazines: A crossnational content analysis. Sex Roles, 64(7-8), 463-474.
Karaian, L., \& Van Meyl, K. (2015). Reframing risqué/risky: Queer temporalities, teenage sexting, and freedom of expression. Laws, $4(1), 18-36$.

Kitchen, A. N. (2015). The need to criminalize revenge porn: How a law protecting victims can avoid running afoul of the first amendment. Chicago-Kent Law Review, 90(1), 247-299.

Klettke, B., Hallford, D. J., \& Mellor, D. J. (2014). Sexting prevalence and correlates: A systematic literature review. Clinical Psychology Review, 34(1), 44-53.

Kline, N. K., Berke, D. S., Rhodes, C. A., Steenkamp, M. M., \& Litz, B. T. (2018). Self-blame and PTSD following sexual assault: A longitudinal analysis. Journal of Interpersonal Violence, advance online publication.

Konstan, D. (2006). The emotions of the ancient Greeks: Studies in Aristotle and classical literature (Vol. 5). University of Toronto Press.

Kosenko, K., Luurs, G., \& Binder, A. R. (2017). Sexting and sexual behavior, 2011-2015: A critical review and meta-analysis of a growing literature. Journal of Computer-mediated Communication, 22(3), 141-160.

Kristeva, J. (2001). Hannah Arendt: Life is a narrative (F. Collins, Trans.). University of Toronto Press.

Laumann, E. O., Gagnon, J. H., Michael, R. T., \& Michaels, S. (2000). The social organization of sexuality: Sexual practices in the United States. University of Chicago Press.

Liben, L. S. (2017). Gender development: A constructivist-ecological perspective. In N. Budwig, E. Turiel, \& P. D. Zelazo (Eds.), New perspectives on human development (pp. 145-164). Cambridge University Press.

Liben, L. S., Bigler, R. S., Ruble, D. N., Martin, C. L., \& Powlishta, K. K. (2002). The developmental course of gender differentiation: Conceptualizing, measuring, and evaluating constructs and pathways. Monographs of the Society for Research in Child Development, 67(2), 1-183.

Lim, M. S., Vella, A. M., Horyniak, D. R., \& Hellard, M. E. (2016). Exploring attitudes towards sexting of young people: a crosssectional study. Sexual Health, 13(6), 530-535.

Linde, C. (2009) Working the past: Narrative and institutional memory. Oxford University Press.

Liong, M., \& Cheng, G. H. L. (2017). Sext and gender: Examining gender effects on sexting based on the theory of planned behaviour. Behaviour \& Information Technology, 36(7), 726-736.

Lippman, J. R., \& Campbell, S. W. (2014). Damned if you do, damned if you don't... if you're a girl: Relational and normative contexts of adolescent sexting in the United States. Journal of Children and Media, 8(4), 371-386.

Lumsden, K., \& Morgan, H. M. (2012). 'Fraping', 'sexting', 'trolling' and 'rinsing': Social networking, feminist thought and the construction of young women as victims or villains. Proceedings of Forthcoming Feminisms.

Malle, B. F., Guglielmo, S., \& Monroe, A. E. (2014). A theory of blame. Psychological Inquiry, 25(2), 147-186.

Mandau, M. B. H. (2020). "Snaps","screenshots", and self-blame: A qualitative study of image-based sexual abuse victimization among adolescent Danish girls. Journal of Children and Media, $1-17$.

Marchal, C., Leys, C., Bernard, P., \& Klein, O. (2013). If it were to happen to me, would I see it coming? How identifying with the victim influences the foreseeability of a sexual aggression. Revue Internationale de Psychologie Sociale, 26(2), 5-28.

Marks, M. J., \& Fraley, R. C. (2006). Confirmation bias and the sexual double standard. Sex Roles, 54(1-2), 19-26.

McCartan, K. F., \& McAlister, R. (2012). Mobile phone technology and sexual abuse. Information \& Communications Technology Law, 21, 257-268. 
McGlynn, C., Johnson, K., Rackley, E., Henry, N., Gavey, N., Flynn, A., \& Powell, A. (2020). 'It's torture for the soul': The harms of image-based sexual abuse. Social \& Legal Studies, advance online publication.

McGlynn, C., Rackley, E., \& Houghton, R. (2017). Beyond 'revenge porn': The continuum of image-based sexual abuse. Feminist Legal Studies, 25(1), 25-46.

Mckinlay, T., \& Lavis, T. (2020). Why did she send it in the first place? Victim blame in the context of 'revenge porn'. Psychiatry, Psychology and Law, advance online publication.

Meyer, M. I. (2016). Let's talk about sext: Gendered millennial perceptions of sexting in a cyborg society (Master's thesis). University of Cape Town.

Miller, A. K., Handley, I. M., Markman, K. D., \& Miller, J. H. (2010). Deconstructing self-blame following sexual assault: The critical roles of cognitive content and process. Violence Against Women, 16(10), 1120-1137.

Miller v. Skumanick. (2009). 605 F. Supp. 2d 634.

Mitchell, K. J., Finkelhor, D., Jones, L. M., \& Wolak, J. (2012). Prevalence and characteristics of youth sexting: A national study. Pediatrics, 129(1), 13-20.

Mori, C., Cooke, J. E., Temple, J. R., Ly, A., Lu, Y., Anderson, N., ... \& Madigan, S. (2020). The prevalence of sexting behaviors among emerging adults: A meta-analysis. Archives of Sexual Behavior, 49, 1103-1119.

Niven, K., Holman, D., \& Totterdell, P. (2012). How to win friendship and trust by influencing people's feelings: An investigation of interpersonal affect regulation and the quality of relationships. Human Relations, 65(6), 777-805.

Nsubuga, J. (2020, June 1). Met Police officer 'asked revenge porn victim for nudes.' Metro.

Nussbaum, M. (1994). Platonic love and Colorado law: The relevance of ancient Greek norms to modern sexual controversies. Virginia Law Review, 80(7), 1515-1651.

Patella-Ray, P. J. (2018). Beyond privacy: Bodily integrity as an alternative framework for understanding non-consensual pornography. Information, Communication and Society, 21(5), 786-791.

Penney, R. (2016). The rhetoric of the mistake in adult narratives of youth sexuality: The case of Amanda Todd. Feminist Media Studies, 16(4), 710-725.

Phillips, K. M. (2018). The breasts of virgins: Sexual reputation and young women's bodies in medieval culture and society. Cultural and Social History, 15(1), 1-19.

Plato. (1974). Republic (G. M. A. Grube, Trans.). Hackett Publishing Company.

Powell, A., Henry, N., \& Flynn, A. (2018). Image-based sexual abuse. In W. S. DeKeseredy \& M. Dragiewicz (Eds.), Routledge Handbook of Critical Criminology (2nd ed., pp. 305-315). Routledge.

Priebe, G., \& Svedin, C. G. (2013). Operationalization of three dimensions of sexual orientation in a national survey of late adolescents. Journal of Sex Research, 50(8), 727-738.

Price, H. (2020, April 24). Coronavirus: 'Revenge porn' surge hits helpline. BBC News. https://www.bbc.com/news/stories-52413994

Reed, L. A., Tolman, R. M., \& Ward, L. M. (2017). Gender matters: Experiences and consequences of digital dating abuse victimization in adolescent dating relationships. Journal of Adolescence, $59,79-89$.

Reese, D. (2013, April 10). The case of Rehteah Parsons: Canada's Steubenville? Washington Post.

Renold, E., \& Ringrose, J. (2011). Schizoid subjectivities? Retheorizing teen girls' sexual cultures in an era of 'sexualization.' Journal of Sociology, 47(4), 389-409.

Ricciardelli, R., \& Adorjan, M. (2019). 'If a girl's photo gets sent around, that's a way bigger deal than if a guy's photo gets sent around': gender, sexting, and the teenage years. Journal of Gender Studies, 28(5), 563-577.
Rice, E., Rhoades, H., Winetrobe, H., Sanchez, M., Montoya, J., Plant, A., \& Kordic, T. (2012). Sexually explicit cell phone messaging associated with sexual risk among adolescents. Pediatrics, 130(4), 667-673.

Richlin, A. (1998). Foucault's History of Sexuality: A useful theory for women?. In D. H. J. Larmour, P. A. Miller, \& C. Platter (Eds.), Rethinking sexuality: Foucault and classical antiquity (pp. 138-170). Princeton University Press.

Ricœur, P. (2013). Souffrance et douleur. Presses Universitaires de France.

Ringrose, J., Harvey, L., Gill, R., \& Livingstone, S. (2013). Teen girls, sexual double standards and 'sexting': Gendered value in digital image exchange. Feminist Theory, 14(3), 305-323.

Rollins, J. (2011). Political science, political sex. Political Science and Politics, 44(1), 27-30.

Rozmarin, M. (2005). Power, freedom, and individuality: Foucault and sexual difference. Human Studies, 28(1), 1-14.

Ruvalcaba, Y., \& Eaton, A. A. (2019). Nonconsensual pornography among U.S. adults: A sexual scripts framework on victimization, perpetration, and health correlates for women and men. Psychology of Violence, advance online publication.

Ruvalcaba, Y., \& Eaton, A. A. (2020). Nonconsensual pornography among US adults: A sexual scripts framework on victimization, perpetration, and health correlates for women and men. Psychology of Violence, 10(1), advanced online publication.

Ruvalcaba, Y., Stephens, D. P., Eaton, A. A., \& Boyd, B. (2020). Hispanic women's perceptions of teenage sexting: qualitative analyses using a sexual scripting framework. Culture, Health \& Sexuality, 1-16.

Salter, M., Crofts, T., \& Lee, M. (2013). Beyond criminalisation and responsibilisation: Sexting, gender and young people. Current Issues in Criminal Justice, 24(3), 301-316.

Scott, A. J., \& Gavin, J. (2017). Revenge pornography: The influence of perpetrator-victim sex, observer sex and observer sexting experience on perceptions of seriousness and responsibility. Journal of Criminal Psychology, 8(2), 162-172.

Setty, E. (2018). Young people's attributions of privacy rights and obligations in digital sexting culture. International Journal of Communication, 12, 4533-4552.

Setty, E. (2019). Meanings of bodily and sexual expression in youth sexting culture: Young women's negotiation of gendered risks and harms. Sex Roles, 80(9-10), 586-606.

Shariff, S. (2014). Sexting and cyberbullying: Defining the line for digitally empowered kids. Cambridge University Press.

Smith, S. H. (2012). Scripting sexual desire: Cultural scenarios of teen girls' sexual desire in popular films, 2000-2009. Sexuality \& Culture, 16(3), 321-341.

Spry, T. (1995). In the absence of word and body: Hegemonic implications of "victim" and "survivor" in women's narratives of sexual violence. Women and Language, 18(2), 27-33.

Statistics Canada. (2019). Annual demographic estimates: Canada, provinces and territories. Statistics Canada catalogue no. 91-215-X.

Strassberg, D. S., McKinnon, R. K., Sustaíta, M. A., \& Rullo, J. (2013). Sexting by high school students: An exploratory and descriptive study. Archives of Sexual Behavior, 42(1), 15-21.

Stroud, S. R. (2014). The dark side of the online self: A pragmatist critique of the growing plague of revenge porn. Journal of Mass Media Ethics, 29, 168-183.

Tanenbaum, L. (2015). I am not a slut: Slut-shaming in the age of the Internet. Harper Perennial.

Thomas, S. E. (2018). "What should I do?": Young women's reported dilemmas with nude photographs. Sexuality Research and Social Policy, 15(2), 192-207.

Thomas, S. E., Weinstein, E., \& Selman, R. L. (2017). Did I cross the line?: Gender differences in adolescents' anonymous digital 
self-reports of wrongdoing in an online anonymous context. Sex Roles, 77(1-2), 59-71.

Thompson, A. E., Hart, J., Stefaniak, S., \& Harvey, C. (2018). Exploring heterosexual adults' endorsement of the sexual double standard among initiators of consensually nonmonogamous relationship behaviors. Sex Roles, 79(3-4), 228-238.

Thompson, A. E., Harvey, C. A., Haus, K. R., \& Karst, A. (2020). An investigation of the implicit endorsement of the sexual double standard among US young adults. Frontiers in Psychology, 11, 1454.

Thurlow, C. (2017). "Forget about the words"? Tracking the language, media and semiotic ideologies of digital discourse: The case of sexting. Discourse, Context \& Media, 20, 10-19.

Todorov, T. (2003). Exposures. The New Republic. https://newrepublic. com/article/66882/exposures

Tolman, D. L. (1994). Doing desire: Adolescent girls' struggles for/ with sexuality. Gender \& Society, 8(3), 324-342.

Uhl, C. A. (2017). The impact of gender, victim weight, and victim responsibility on attributions of blame and responsibility in a case of nonconsensual pornography (Doctoral dissertation). University of North Dakota.

U.S. Census Bureau. (2019). Annual estimates of the resident population for selected age groups by sex for the United States, states, counties, and Puerto Rico commonwealth and municipios: April 1, 2010 to July 1,2018 . Author.

Uhl, C. A., Rhyner, K. J., Terrance, C. A., \& Lugo, N. R. (2018). An examination of nonconsensual pornography websites. Feminism and Psychology, 28(1), 50-68.

Ullman, S. E. (1996). Social reactions, coping strategies, and selfblame attributions in adjustment to sexual assault. Psychology of Women Quarterly, 20(4), 505-526.
Van de Rijt, A., \& Buskens, V. (2006). Trust in intimate relationships: The increased importance of embeddedness for marriage in the United States. Rationality and Society, 18(2), 123-156.

Van Ouytsel, J., Van Gool, E., Walrave, M., Ponnet, K., \& Peeters, E. (2017). Sexting: Adolescents' perceptions of the applications used for, motives for, and consequences of sexting. Journal of Youth Studies, 20(4), 446-470.

Van Royen, K., Poels, K., Vandebosch, H., \& Walrave, M. (2018). Slut-Shaming 2.0. In M. Walrave, J. Van Ouytsel, K. Ponnet, \& J. R. Temple (Eds.), Sexting (pp. 81-98). Palgrave Macmillan.

Vera-Gray, F., \& Fileborn, B. (2018). Recognition and the harms of "Cheer Up". The Philosophical Journal of Conflict and Violence, 2(1), 78-95.

Webb, A. (2019). Why Bella Thorne deserves support, not shame, for sharing nudes. Study Breaks.

Weiss, K. G. (2010). Too ashamed to report: Deconstructing the shame of sexual victimization. Feminist Criminology, 5(3), 286-310.

Whisnant, R. (2010). From Jekyll to Hyde: The grooming of male pornography consumers. Philosophy Faculty Publications, 93, 114-133.

Yar, M., \& Drew, J. (2019). Image-based abuse, non-consensual pornography, revenge porn: A study of criminalization and crime prevention in Australia and England \& Wales. International Journal of Cyber Criminology, 13(2), 578-594.

Publisher's Note Springer Nature remains neutral with regard to jurisdictional claims in published maps and institutional affiliations. 